\title{
Discourse of Inclusion in the Complexity Era: In the BRICS Space
}

\author{
Dr Natalia E. Sudakova ${ }^{+*}$ and Dr Olga N. Astafyeva ${ }^{¥}$
}

\section{Abstract}

The relevance of the study is explained by the need to comprehend the expansion of the inclusion discourse in the situation of continuing complication of socio-cultural interaction in the BRICS countries. The modern society's growing need to create an inclusive community, which professes the values of diversity, is associated with the complication of the socio-cultural landscape. The concept of inclusion complexity as a form of thinking that diagnoses and overcomes the devaluation of a person in all possible contexts are presented in the research by the example of the diverse experience of inclusive initiatives' deployment in the BRICS countries. The authors emphasise that an adequate study of this phenomenon is impossible outside the study of each country's sociocultural experience. For optimal results, it was essential to analyse and describe the processes of inclusion formation in the BRICS format in the context of comparing existing approaches. It allowed both to identify the national specifics and to identify the universal mechanisms of inclusion formation as of a modern cultural phenomenon. The authors conceptualize the need to maintain dependencies between different types of social experience in South Africa, which reveals the importance of a comprehensive approach to overcoming existing problems connected with poverty, inequality, gender issues, and existing unemployment. The research describes the experience of implementing the inclusion policy in the sphere of culture and education in Brazil and India. Various aspects of inclusion formation in China are revealed: it is emphasized that the negative attitude towards people with health disorders is due to the socio-cultural context. The problems of financial inclusion are considered in the context of the experience of their solvation in China and India. The authors turn to the diverse experience of implementing inclusive initiatives in Russia, demonstrating the complexity of inclusion formation as a new form of humanistic thinking.

Keywords: Inclusion; Complexity; Thinking; BRICS; Other

\footnotetext{
${ }^{\dagger}$ Associate Professor, Russian Presidential Academy of National Economy and Public Administration; Director, Institute of Pedagogy, Psychology and Philosophy of Education, Moscow Academy of Professional Competencies, Moscow, Russia

${ }^{*}$ Corresponding Author, Email: sovetnik.imtp@mail.ru

¥ Professor, Russian Presidential Academy of National Economy and Public Administration, Moscow, Russia

(C) 2020 Sudakova \& Astafyeva. This is an Open Access article distributed under the terms of the Creative Commons Attribution License (http://creativecommons.org/licenses/by/2.0), which permits unrestricted use, distribution, and reproduction in any medium, provided the original work is properly cited.
} 


\section{Introduction}

The relevance of the inclusion discourse expansion is due to the understanding that its modern study in most cases is limited to some particular aspect. It does not take into account all its other components and it certainly needs to be overcome. This observation applies to educational, social, economic, and any other form of inclusion values' representation. This statement gradually acquires its fullness, because for the first time in the history of human civilization development, society changes the idea of 'truly human', bringing the many-sided Other to the forefront, who, like another culture, is raised to a self-value. This situation is determined by a significant increase in the need to understand and accept the diverse sociocultural experience of Another, which contributes to the strengthening of positions of inclusion as the core of the new humanism, expressed in the transformation of modern human's thinking.

Nevertheless, the argument is of particular importance in the complexity era, which has been designated by E. Laszlo (1994) as "macroshift" and as "elusive world" by E. Giddens (1990). Inclusive initiatives, actively spreading across the planet, reflect the complex nature of the complex phenomena, as they fit into the post-non-classical paradigm of synergetic complexity, which takes its methodological basis in G. Deleuze \& F. Guattari (2010) and E. Morin's theories (2011). In this regard, it is worth noting that the integrity of culture is provided today by the grounds where chaotic state, complexity and emergence of its development actively declare themselves (Astafyeva et al., 2009).

Reasoning within the framework of complexity paradigm, we shall note that as if overcoming the semantic uncertainty, culture is growing today with a new anthropologic-socio-cultural system-inclusion, which has the character of a worldview universal (Sudakova \& Astafyeva, 2019). Inclusion is gradually determined as a form of complex thinking, asserting the absolute value of each person for the development of all humanity in all possible aspects, including economic, social, and educational. This phenomenon reveals the increasing use of its resources in various spheres of social life, including business programs based on the principles of opportunities, equal for everybody. This context is entirely in line with the 2030 Sustainable Development Goals (2015), where the focus is on achieving inclusive diversity spread across continents and measured today by the inclusive development index.

No less important is the understanding that the phenomenon of inclusion translates its complicated structure through the nonlinearity and the dichotomy of its deployment, through its emergence, mosaic, and ambiguity of constantly arriving inclusive initiatives. They are aimed at the development of particular humanistic thinking, diagnosing, and overcoming the vulnerability of each other vertically (in valuesemantic axiological aspect), and horizontally (in the space-time embodiment), the deployment of socio-cultural contemporary reality.

Paying attention to the formation of inclusion as a phenomenon, we shall note that the focus on any particular component of this problem prevents both its holistic perception and the development of an adequate strategy of inclusive policies that strengthen the position of social justice. Thus, it is impossible to fill the discourse of inclusion adequate to the modern development without the system-synergetic research methodology based on the interdisciplinary approach, verified by philosophical-anthropological and cultural approaches. The materials and methods deployed for this study are discussed in the following section.

\section{Materials and Methods}

The specific need conditions the choice of the methodological base of the research for a systematic analysis of socio-cultural reality as a basis for understanding the importance of inclusive culture formation in modern society and developing strategies for its formation. For optimal results, it was essential to analyse and describe the processes of inclusion formation in 
the BRICS format in the context of comparing existing approaches, which allowed both to identify the national specifics and to identify the universal mechanisms of inclusion formation as a phenomenon of modern culture.

The need to comprehend the constant complication of the inclusion discourse in the BRICS socio-cultural space predetermined the purpose of this research, that is substantiating the importance of the interdisciplinary systemsynergetic approach to its study. This approach allows revealing the complex nature of the inclusion phenomenon aimed at overcoming the depreciation of a person in various aspects of life.

For the full realisation of this purpose, the following tasks were identified:

1. to compare the processes of inclusion formation in the BRICS countries allowing not only to reveal the intranational specificity and ambiguity of its ongoing development, but also the mechanisms of its representation as a universal of modern culture;

2. to reveal the interdependence of social experience in implementing inclusive initiatives on the example of the BRICS countries, where a full resolution of the existing problems of person's depreciation cannot be realised without overcoming a complex of problems concerning poverty, inequality, gender and any other discrimination, including the aspect of unemployment;

3. to describe and compare the basic principles for implementing inclusive initiatives in the BRICS countries with a focus on their implementation experience in Russia and China.

For the realisation of this purpose we have chosen the principle of multi-paradigmatic approach theorising (Taylor, 2008), which reveals the process of inclusion formation in the context of hybridity and cross-border worldview, in the context of the newly formed identity, contributing to the establishment of a culture of diversity in the modern world.

The authors formed a plan, the first stage of which allowed to analyze and reveal the specifics of inclusion formation as a complex form of thinking, where there was no task to identify the correlation between the variables. However, there was a need to determine the general mechanisms for the inclusive initiatives' deployment. To solve this problem, the authors presented the results of a comparative analysis of studies on inclusive practices' deployment in the BRICS countries. The use of the comparative method in the study of macrospace and interspatial processes is, according to S. N. Eisenstadt (1968), the only adequate method of research, which is consistent with the position of the editors D. Porta \& M. Keating (2008, p.202), as well as with the position of the authors of this study. This approach allowed to reveal the onesidedness of scientific ideas about the inclusion deployment, based on the study of some single aspect.

The next stage was devoted to the analysis of the reflection of the Chinese and Russian sociocultural models, where inclusive practices have been rapidly gaining momentum in recent decades. Comparative analysis of the selected approaches allowed us to trace the complexity of inclusive practices deployment in the BRICS countries.

The main methods were the method of comparison, socio-cultural, functional and system analysis. The last of these methods, in particular, allows us to show the phenomenon of inclusion as a holistic phenomenon, through the prism of complex relationships of social communications and cultural practices.

\section{Inclusion Discourse in BRICS Countries: Towards a Comprehensive Inclusion Methodology}

The increasing need for social cohesion, driven by high levels of inequality, poverty, discrimination and violence in BRICS countries, requires recognition of the serious interdependence between all types of social experience, including its economic, cultural, political and other components. This important aspect for all countries of the modern world, acquires a special meaning in the context of growing complex socio-cultural relations between the nations, where both the processes 
of multiculturalism and the aspirations to preserve cultural sovereignty are unfolding in parallel.

G. Hagg and P. Kagwanja (2007), in their study of South Africa, emphasize the preservation of interdependence between different types of social experience. The scientists specialized in the issues of cultural diversity in the context of community development. In their opinion, internal conflicts based on identity problems, require the development of new approaches to their escalation elimination (Hagg \& Kagwanja, 2007).

In this perspective, the inclusive initiatives rapidly spreading around the world have every reason to form a new form of humanistic thinking that helps to overcome the growing threats and destructions, where the BRICS countries are no exception. The promotion of inclusive initiatives in Brazil, India, Russia, China and South Africa is not only universal, but also unique, due to the historical and cultural characteristics of the regions, the public perception of inclusion and public policy towards the most vulnerable segments of the population. At the same time, the development of educational programs that meet the inclusive standards adopted throughout the world becomes the main tool for the formation of complex inclusive thinking on the BRICS territory.

The first and most vulnerable target of inclusion in all BRICS regions is people with different forms of health deficits, gradually gaining value for the development of the entire community. At the same time, many contexts of overcoming human vulnerability as of another are now on the surface, including in the BRICS countries, where they are mediated by the problems of poverty, health disorders, gender, racial and other forms of discrimination. This perspective reveals the need to ensure the right of each individual to self-improvement, self-actualisation, creativity and social realization.

Considering this aspect on the example of the most economically developed province of South Africa, B. Kanyane and colleagues (2017a) shows how the problems of the six most vulnerable groups come to the fore: women in need of empowerment, war veterans, migrants, the youth, the elderly, as well as people with disabilities. All these groups need to develop effective inclusive policies aimed at ensuring the protection of human rights and leading to the strengthening of positions of social justice, eliminating social imbalances. It is this comprehensive, holistic and integrated approach to research of vulnerable groups' problems that is highlighted in South Africa's strategic documents (Kanyane et al., 2017b).

An integrated approach to the study of overcoming existing problems in relation to poverty, inequality, gender issues, as well as the existing unemployment in South Africa is also applied by C. Ndinda \& T. P. Ndhlovu (2018) as well as by M. Z. Phiri and colleagues (2015). Gender inequality problems, which are, according to Z. Khuzwayo (2014), derivatives of the patriarchate culture, dominant in South Africa, certainly cannot be solved without promoting inclusive mindset formation which would overcome existing devaluation of women, which also actualises the proposed approach to inclusion as a complex form of humanistic thinking.

Studying the socio-cultural space of India, we shall turn to the 'Inclusive India Initiative' (2017) developed by the National Trust under the Ministry of Social Justice and Empowerment, committed to inclusive education, empowerment and social life for people with intellectual disabilities and development. According to its organisers' idea, this initiative involves about 2,000 organisations of the corporate sector, both public and private, promoting the employment of people with disabilities.

Open models of network sociality in Brazil are characterized by digital inclusion, which expands access to the consumption of media technologies by marginal segments of the population. Government support for digital inclusion in culture and education, according to Heather A. Horst (2011), caused the emergence of a new understanding of social justice in the society, overcoming social and digital 
differences. This aspect does not exhaust the contexts of research and implementation of inclusive policies in Brazil. Exploring this problem, M. N. Htun (2003) draws our attention to sexual and racial discrimination in Brazil, which forms the discourse of inclusion in this country. The high level of poverty in Brazil is another challenge of inclusive policies that aim to stimulate the activities of the 16 million people living in extreme poverty (Productive Inclusion in Brazil, 2014). At the same time, the policy of inclusive education has been actively implemented in this country since 2003, which has both positive and negative consequences (Cenci et al., 2016). All of them to some extent reflect the emergence of inclusion in the society. It is a socio-cultural tool that promotes the recognition of the equivalence of the needs and opportunities of each person for the whole community development.

This aspect confirms the formation of a complex form of thinking in society, designed to diagnose and build ways to overcome the emerging vulnerability in all possible contexts.

Considering various aspects of inclusion formation study in the BRICS countries, we draw attention to the fact that a full understanding and prediction of its development based on it are difficult outside the complex methodological tools of system-synergetic, namely, interdisciplinary character.

\section{China and Russia: Towards an Inclusive Community}

The transformation of the education systems in China and Russia has the same grounds as in other BRICS countries, as it fully meets the strategic initiatives of UNESCO regulating global education reforms from an inclusive perspective.

Let us pay attention to the number of people with disabilities in the People's Republic of China. According to the result of the second national sampling survey on disability conducted in 2006, there are about 82, 96 million PWDs in China, accounting for $6.34 \%$ of the total population. Among them: 12.33 million persons with visual impairment (14.86\%); 20.04 million persons with hearing impairment (24.16\%); 1.27 million persons with speech disabilities (1.53\%) (Huiping, 2019:3).

Interpreting the attitude to disability in China, we note that religious beliefs seriously influence its formation, thus, the problem of disability cannot be considered outside the context of significant Confucianism and Buddhism (Chan, 1992). Negativity towards people with health deficits is shaped by sociocultural reasons and is compounded by parents avoiding their child's social contacts (Huang and Wheeler, 2007). This attitude has created stereotypes about all people with disabilities that have pushed inclusive initiatives into the background.

At the same time, in the 80ies, China for the first time introduced programs of training people with disabilities in the higher school that led to the fact that by the end of 2016 there were 21 higher educational institutions for persons with health disabilities. Adopted in 1990 and amended in 2008, Law of the People's Republic of China on the Protection of Disabled Persons (1990) and also Regulations on the Education of Persons with Disabilities (1994) contributed to the expansion of inclusion positions in this country.

Gender equality issues are also becoming more relevant in China, where equal opportunities for women are given special attention. The 2030 Sustainable Development Goals (2015) set the tone for an inclusive global economy, where China's initiatives are expanding significantly. At the same time, economic growth requires reforming the entire education system, which is important for both China and Russia. Adopted in Qingdao in 2015, the Declaration reflects the new vision of Education 2030, calls on communities to build inclusive knowledge societies based on equitable and inclusive access to quality education for everybody throughout life. Inclusiveness and accessibility are declared a priority where "technology provides unprecedented opportunities to bridge the learning gap" (Qingdao Declaration, 2015: Seize Digital Opportunities, Lead Education Transformation, 2015, p.32). According to this document, ICTs contribute to gender equality, help people with health problems to gain 
maximum access to education and opportunities for self-realization.

A skilled workforce cannot be a priority without creating an inclusive mindset in the society that can broadcast the values of diversity, social justice and the importance of each individual. The variety of problems and contexts of human devaluation, the variety of socio-cultural experience predetermines the complexity of the tools for an inclusive attitude formation towards the Other.

In China, along with the state initiatives, UNESCO ones are being implemented to eliminate inequality from different sides, including in terms of support for migrants. In 2001, the project of the pilot study Together with migrants to eradicate poverty in China (2010, p.21) revealed the problem of rural migrants' integration into the urban community. In May 2009, Beijing, supported by the UN, launched a three-year $\$ 7$ million project to support young migrants from rural areas. Since 2004 migration flows of young Chinese with only incomplete secondary education have increased and become a serious problem for the Chinese economy. They are not only providing cities with cheap labour, but also exacerbating the conflict component caused by the increasing gaps in wealth and opportunities for self-realisation (China: UNESCO pilot project on the rights of young migrants, 2009).

Different aspects of inclusive initiatives' implementation in the field of digital economy, where the concept of inclusive finance is actively growing, are really demanded: $95 \%$ of China's population have access to the Internet in their mobile devices (FinTech and Financial Inclusion in China, 2017), and can also count on a variety of instruments of the financial lending. Inclusive innovation gradually increases access to basic goods and services for all people, improving their quality of life and creating new opportunities to meet the needs. This aspect is important, as the growing inequality between the poor and the rich creates new threats. That is, "China's rapid and consistent economic growth over the past several decades substantially reduced the number of people living in poverty, but sharply increased income inequality" (Document of the World Bank. China. Inclusive innovation for sustainable inclusive growth, 2013: 7). This increase is also noticeable in the context of a 13fold spread in the incomes of the poor and the rich, which certainly limits the opportunities for the poor to exercise their rights. However, more than $\mathbf{2 3 0}$ million adults without banking services face funding shortfalls. The same problem is revealed in India in the studies by R. R. Singareddy and colleagues (2019). But under Pradhan Mantri Jan Dhan about 318 million bank accounts were opened (Bhattacharyya \& Pulla, 2019).

Thus, the problems of inclusion cannot be considered outside the problems of poverty. To solve this problem, we need a purposeful state policy, where inclusive growth acts not only as a valuable component of a civilised society, but also as a tool for a smart economy formation. This would overcome the problem of social imbalance and contribute to the economic development of the society in which each member would bring its feasible but productive contribution. The development of a holistic, inclusive innovation strategy would allow achieving maximum results for the implementation of the 2030 Goals.

Inclusion in Russia is developing no less rapidly, revealing the need for transformation of ideological constructs, traditional for this country. In the Russian context, the idea of inclusion, as including education for children with disabilities and invalids, proved to be very popular, as statistics show that the number of officially disabled on 01 January, 2018 amounted to more than 12.1 million - almost $9 \%$ of the total population of the Russian Federation. Of them, only 1.6 million people have a job (Federal State Statistics Service. The situation with persons with disabilities, 2019). These figures accurately reflect the current state of affairs associated with a serious social exclusion of people with any deficits in Russian society. The situation is exacerbated by the fact that in modern conditions of a new high-tech reality deployment, when most people have access to the advanced results of human creativity, people 
with deficits are below the poverty line, forced to become a tangible social burden on the society.

These rationales force modern society to state the violation of disabled people's rights for decent life. They include the opportunity to get education in the field of their abilities, to work for leading independent life without losing human dignity, to have friends and family, and thus to be a full participant of social interaction. It is obvious that the identified problems cannot be overcome without the use of a systematic approach. This approach is primarily associated with the reassessment of attitudes towards people, including those with different forms of deficits, but with a potential for creative transformation of the existing world by the right of birth and development for the benefit of the individual and society. Systematic approach involves the creation of the environment for each participant (including those with deficits) of social interaction, which does not limit his/her access to all existing tools of social selfrealisation.

Modern Russia demonstrates the rapid growth of inclusive initiatives in all areas of life, which symbolises the increased activity of society in solving problems on overcoming social imbalances. In 2012, a new law "On education" (2012) was adopted, which launched a legal mechanism for the implementation of the inclusive education idea, which has received a significant spread over the past time. Changes in the work of educational institutions, associated with the spread of inclusive approach at all existing levels of education, are actively supported by all regions of the Russian Federation, seeking modernization of their life systems to adequately respond the acute challenges.

The implementation of this approach is not an easy task a sit significantly exacerbates the existing socio-cultural and economic gaps. The idea of building an inclusive community collides with the existing reality, which further tests the depth of its potential as a universe of culture. Russian society is going through regular stages of inclusion formation as a cultural phenomenon, the discourse of which is ambiguous, but this is why it is inclusive in nature.

At the same time, the formation of the sociocultural reality of the new format, due to inclusive values, is very uneven, as can be seen from the many processes taking place in different areas. The entry of Russia into a single socio-cultural space and awareness of the ideological essence of the problem of the disabled people's devaluation have led to the emergence of a large number of public organisations. Many of them are currently largescale non-profit partnerships that support people with disabilities.

Thus, inclusion expands the idea of itself in various contexts, forming an actual complex discourse of the possibilities of its realization. Modern reality reveals a significant scaling of inclusion as a universal culture in many forms of horizontal and vertical deployment, where each form becomes the beginning of a new life, another cycle of inclusion. This is evident both in global trends and in the development of inclusion in the Russian socio-cultural space. Together with the state programs of inclusive education development in Russia, also expressed in the National Strategy of actions in children's interests for 2012-2017 (2012), the Strategy of Education Development in the Russian Federation for the period until 2025 (2015), the state program - Accessible environment until 2020 (2015) there is considerable public support for the idea of inclusion.

The activities of such organisations demonstrate the growth of public inclusive initiatives as "White cane", which forms a new form of inclusion - the philosophy of extrability, as a space of additional opportunities for people with health deficits arising in the process of the body compensatory functions' inclusion (Extrability, 2019). This organization is engaged in the implementation of many projects aimed at the formation of inclusive thinking both in Russia and in the global format. With their active assistance, the first World Congress of people with disabilities was held in Yekaterinburg in 2017, which was attended by 700 people from 
28 countries and 23 regions of the Russian Federation.

The autonomous non-commercial organisation Center for socio-cultural animation "Spirituality" (CSA), opened in 2002, created for the inclusion of people with disabilities into the full life using socio-cultural animation, became one of the most significant inclusive business projects in Russia. CSA annually holds about 40 events that promote the values of inclusion. Among them there is the international charity dance festival Inclusive Dance (n.d.) which united more than 100 groups and 2000 participants from 15 countries within six years of its existence.

All these projects show that the complexity of inclusion is due to its ability to self-building, where "a rhizome may be broken, destroyed in any place, but it resumes, following one or another lineage, and following its other lines" (Deleuze \& Guattari, 2010, p.16).

Any product of inclusion may cease to exist, lose its relevance. However, the idea of inclusion itself, possessing recursiveness, will be reproduced again and again, as we see at the moment around the world, in all possible aspects.

\section{Conclusion}

The nature of the unsettling phenomenon of inclusion determines a complex, interdisciplinary approach to the methodology of its study, where there is a need to overcome the insolvency of the existing fragmentation of inclusion reflection caused by the diversity of its definitions and continuous development, which has a complex, ambiguous nature.

Understanding the complexity of the phenomenon under study, which has the features of ideological universals of modern culture, requires the use of a system-synergetic approach based on the reflection of its manifestation in the socio-cultural practice of the BRICS countries.

The study revealed the complexity of this phenomenon, which organically combines holistic-network structuring, recursive development, emergent transformations, fractality of space-time deployment, contributing to the ongoing development of inclusion, which has the ability to replicate and self-build, due to the rapid scaling of sociocultural inclusive initiatives around the world, including in the space of BRICS.

\section{References}

Approaches and Methodologies in the Social Sciences. A Pluralist Perspective (2008). Porta, D. \& Keating, M. (Eds.). Cambridge: Cambridge University Press. Retrieved on 29 August 2019 from, https://www.hse.ru/data/2012/11/03/1249193 115/Donatella_Della_Porta_Michael_Keating_A pproa.pdf

Astafyeva, O.N. \& Arshinov, V.I., Budanov, V.G. \& Svirsky, Ya.L. (2009). Synergetic Paradigm. Moscow: Progress-Tradiciya.

Bhattacharyya, R., \& Pulla, V. (2019). Prime Minister Modi Returns, 2019: New Governance Agenda. Space and Culture, India, 7(1), 1-14, https://doi.org/10.20896/saci.v7i1.569

Cenci, A., Vilas Bôas D.F. \& Damiani, M.F. (2016). The challenge of inclusive education in a Brazilian School: teachers' concerns regarding inclusion. Research, Society and Development, 2(2), 94-106.

Chan, S. (1992). Families with Asian Roots. Developing Cross-Cultural Competence (pp. 181258). Baltimore: P.H. Brookes.

China: UNESCO pilot project on the rights of young migrants. (2009). SHSviews, 25, 10.

Retrieved on 28 August 2019 from, https://unesdoc.unesco.org/ark:/48223/pf0000 183490

Deleuze, G. \& Guattari, F. (2010). The Thousand Plateaus: Capitalism and Schizophrenia. Yekaterinburg: U-Factoria; Moscow: Astrel.

Document of the World Bank. China. Inclusive innovation for sustainable inclusive growth (2013). Retrieved on 30 August 2019 from, https://openknowledge.worldbank.org/bitstrea $\mathrm{m} /$ handle/10986/26333/revised08251900Box0 382083B00PUBLICO.pdf? sequence $=1$ \&isAllowed $=y$ 
Eisenstadt, S.N. (1968). The Protestant Ethic and Modemization: A Comparative View. New York: Basic Books.

Federal State Statistics Service. (2019). The situation with persons with disabilities.

Retrieved on 29 August 2019 from, https://www.gks.ru/folder/13964

FinTech and Financial Inclusion in China (2017). Retrieved on 30 August 2019 from, https://iems.ust.hk/tlb20

Giddens, A. (1990). The Consequences of Modernity. Cambridge: Polity Press.

Hagg, G. \& Kagwanja, P. (2007). Identity and Peace: Reconfiguring Conflict Resolution in Africa. African Journal on Conflict Resolution, 7(2), 9-35.

Horst, H.A. (2011). Free, Social, and Inclusive: Appropriation and Resistance of New Media Technologies in Brazil. International Journal of Communication, 5, 437-462.

Htun, M.N. (2003). Dimensions of Political Inclusion and Exclusion in Brazil: Gender and Race. Retrieved on 30 August 2019 from, http://iknowpolitics.org/sites/default/files/dim ensions_of_political_inclusion_and_exclusion_i n_brazil.pdf

Huang, A.X., \& Wheeler, J.J. (2007). Including children with autism in general education in China. Childhood Education, 83, 356-360.

Huiping, C. (2019). The Development of ICT Accessibility for Persons with Disabilities in China. Retrieved on 28 August 2019 from, https://www.un.org/disabilities/documents/eg m2012/Cui.PresentationPPT.pdf

Inclusive dance. (n.d.). Retrieved on 28 August 2019 from, http://inclusive-dance.ru/ru/

Inclusive India Initiative (2017). Retrieved on 29 August 2019 from, https://pib.gov.in/newsite/PrintRelease.aspx?re lid=164434

Kanyane, B., Bohler-Muller, N., Hagg, G., Chiumbu, S., Hart, T., Makiwane, M., Steyn, J., Kotze, S., Houston, G., Pophiwa, N., Gordon,S., Alubafi, F., Ngungu, M., Zikhali, T., Viljoen, J., Wentzel, M., Mdlongwa, T., Raseala, P., Majozi,
N. (2017a). Gauteng transformation policy

framework on vulnerable and designated groups 2016-2020: a situation analysis report.

Retrieved on 30 August 2019 from, http://www.hsrc.ac.za/en/researchoutputs/view/8615

Kanyane, B. \& Hagg, G. \& Raseala, P. (2017b). Gauteng transformation policy framework on vulnerable and designated groups 2016-2020: theory of change: final report. Retrieved on 30 August 2019 from,

http://www.hsrc.ac.za/en/researchoutputs/view/8748

Khuzwayo, Z. (2014). Addressing gender inequality. South African Labour Bulletin. Retrieved on 27 August 2019 from, http://www.hsrc.ac.za/en/researchoutputs/view/7106

Law of the People's Republic of China on the Protection of Disabled Persons (1990). Retrieved on 27 August 2019 from, https://www.ilo.org/dyn/natlex/docs/WEBTEXT /31906/64869/E90CHN01.h

Laszlo, E. (1994). Macroshift: Navigating the Transformation to a Sustainable World. San Francisco: Berrett-Koehler Publishers, Inc.

Morin, E. (2011). On the abyss? SaintPetersburg: Aletheia.

Ndinda, C., \& Ndhlovu, T.P. (2018). Gender, poverty and inequality: exploration from a transformative perspective. Journal of International Women's Studies, 19 (5), 1-12.

On the National strategy of actions in children's interests for 2012-2017(2012). Retrieved on August 302019 from, http://base.garant.ru/70183566/

Phiri, M. Z. \& Molotja, N. \& Makelane, H. \& Kupamupindi, T. \& Ndinda, C. (2015). Inclusive innovation and inequality in South Africa: a case for transformative social policy. Retrieved on August 302019 from, https://www.researchgate.net/publication/279 159847_Inclusive_innovation_and_inequality_i n_South_Africa_A_case_for_transformative_so cial_policy 
Qingdao Declaration, 2015: Seize Digital Opportunities, Lead Education Transformation (2015). Retrieved August 302019 from, https://unesdoc.unesco.org/ark:/48223/pf0000 233352

Regulations on the Education of Persons with Disabilities (1994). Retrieved 30 August 2019 from: https://www.cecc.gov/resources/legalprovisions/regulations-on-the-education-ofpersons-with-disabilities

Singareddy, R.R. \& Ranjan, P. \& Annamalai, B. \& Chandrasekaran, S. (2019). Financial Inclusion Remodeling: Including the Excluded Masses. Space and Culture, India, 6(5), 178-188, https://doi.org/10.20896/saci.v6i5.375

Strategy of education development in the Russian Federation for the period until 2025 (2015). Retrieved on 30 August 2018 from, http://council.gov.ru/media/files/41d536d68ee 9fec15756.pdf

Sudakova, N.E. \& Astafyeva, O.N. (2019). Inclusion as a Modern Cultural Universal: Reflection and Conceptualization. Journal of Social Studies Education Research, 10(3), 212235.

Taylor, P.C. (2008). Multi-Paradigmatic Research Design Spaces for Cultural Studies Researchers Embodying Postcolonial Theorizing. Culture Studies of Science Education, 3(4), 881890.
The Law on Education (2012). Retrieved on 28

August 2019 from, http://www.lexed.ru/en/education-law-inrussia/the-law-on-education/

The state program of the Russian Federation "Accessible environment" for 2011-2020 (2015). Retrieved on 30 August 2019 from, http://static.government.ru/media/files/6kKpQ JTEgR1Bmijjyqi6GWqpAoc60mnC.pdf

Productive Inclusion in Brazil (2014). Retrieved on 30 August from, https://www.worldbank.org/en/results/2014/0 5/29/brazil-productive-inclusion-effortsincrease-equality

"Together with migrants" to eradicate poverty in China. (2010). SHSviews: special issue, 21. Retrieved on 29 August 2019 from, https://unesdoc.unesco.org/ark:/48223/pf0000 187407

Sustainable Development Goals (2015).

Retrieved on 27 August 2019 from, https://www.undp.org/content/dam/undp/libr ary/corporate/brochure/SDGs_Booklet_Web_E n.pdf

Extrability (2019). Retrieved on 27 August 2019 from, https://extrability.org/about/extrability/

\section{Acknowledgements}

The paper was prepared in the framework of RFBR grant 19-511-93002 KAON_a "Cultural and philosophical bases of Chinese-Russian cooperation". 